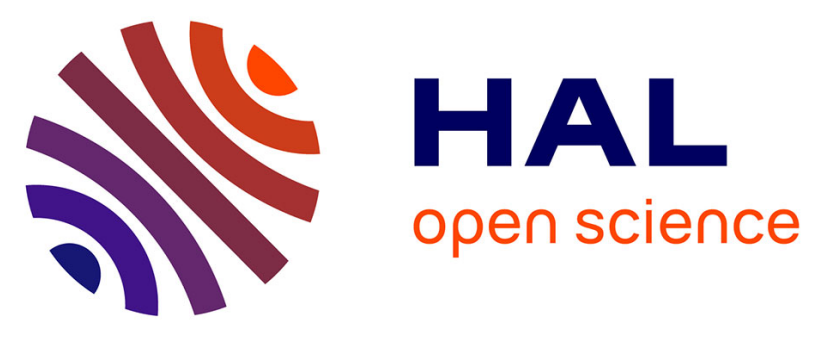

\title{
Efficient degradation of the organic UV filter benzophenone-3 by Sphingomonas wittichii strain BP14P isolated from WWTP sludge
}

Sonja K. Fagervold, Clémence Rohée, Alice M. S. Rodrigues, Didier Stien, Philippe Lebaron

\section{To cite this version:}

Sonja K. Fagervold, Clémence Rohée, Alice M. S. Rodrigues, Didier Stien, Philippe Lebaron. Efficient degradation of the organic UV filter benzophenone-3 by Sphingomonas wittichii strain BP14P isolated from WWTP sludge. Science of the Total Environment, 2021, 758, pp.143674. 10.1016/j.scitotenv.2020.143674 . hal-03217024

\section{HAL Id: hal-03217024 \\ https://hal.science/hal-03217024}

Submitted on 4 May 2021

HAL is a multi-disciplinary open access archive for the deposit and dissemination of scientific research documents, whether they are published or not. The documents may come from teaching and research institutions in France or abroad, or from public or private research centers.
L'archive ouverte pluridisciplinaire HAL, est destinée au dépôt et à la diffusion de documents scientifiques de niveau recherche, publiés ou non, émanant des établissements d'enseignement et de recherche français ou étrangers, des laboratoires publics ou privés. 
1 Efficient degradation of the organic UV filter benzophenone-3 by Sphingomonas

2 wittichii strain BP14P isolated from WWTP sludge

4 S. K. Fagervold ${ }^{1 *}$, C. Rohée ${ }^{2}$, A. M. S. Rodrigues ${ }^{1}$, D. Stien ${ }^{1}$ and P. Lebaron ${ }^{1}$

$6 \quad{ }^{1}$ Sorbonne Université, CNRS, Laboratoire de Biodiversité et Biotechnologies

7 Microbiennes, LBBM, Observatoire Océanologique, 66650 Banyuls-sur-mer, France

$8 \quad 2$ Pierre Fabre Dermo-Cosmétique, Centre de Recherche \& Développement Pierre

9 Fabre, 31000 Toulouse

$11{ }^{*}$ Corresponding author: Sonja K. Fagervold. fagervold@obs-banyuls.fr.

12 Address: Observatoire Océanologique de Banyuls, Laboratoire de Biodiversité et

13 Biotechnologies Microbiennes, Avenue Pierre Fabre, 66650 Banyuls/mer, France

\section{Abstract}

17 Benzophenone-3 (BP3) is a widely used organic UV filter present in many

18 environmental compartments. One way BP3 is released into the environment is

19 through effluents from wastewater treatment plants (WWTPs). These plants are

20 possible sources for degradation activity as WWTP sludge can potentially degrade

21 BP3. Our goal was to identify the BP3 degrading microorganism(s) in WWTP sludge

22 and to investigate whether the degradation was co-metabolic. Initial WWTP sludge

23 microcosms spiked with BP3 showed 100\% degradation after 20 days. Multiple 
24 transfers of these microcosms, while maintaining a strong selective pressure for

25 BP3 degradation capabilities, resulted in the dominance of one bacterial strain. This

26 strain, Sphingomonas wittichii BP14P was subsequently isolated and shown to

27 degrade BP3 in a growth dependent manner. Strain BP14P utilized BP3 as the sole

28 energy and carbon source and completely degraded BP3 after 7 days in minimal

29 media. We tested the capability of BP14P to degrade nine other UV filters, but the

30 degradation ability seemed to be restricted to BP3. However, whether this

31 specificity is due to the lack of degradation genes, cellular transport or low

32 bioavailability of the other UV filters remained unclear. The efficient degradation of

33 BP3 by a group of bacteria well known for their potential for xenobiotic degradation

34 is an important step forward for a complete risk assessment of the long-term

35 environmental impact of BP3.

37 Keywords: Sunscreens, BP3 degradation, growth-dependent, Sphingomonas

38 wittichii

\section{1. Introduction}

41 Benzophenone-3 (BP3) is an organic UV filter commonly used in sunscreen

42 formulations and other cosmetic products. Due to its widespread use, BP3 is now

43 found in many environmental compartments such as freshwater and seawater,

44 benthic sediments and aquatic biota (see Mao et al. (2018) for a recent review).

45 Further, BP3 has been found in bird eggs (Molins-Delgado et al., 2017) and even in

46 human breast tissue (Barr et al., 2018) suggesting that BP3 can biomagnify. Also, it 
47 has been demonstrated that BP3 can be absorbed through the skin but the effects of

48 elevated systemic BP3 concentrations in humans are still unclear (Suh et al., 2020).

49 BP3 has been shown to be toxic in several species used for toxicological testing

50 including fish, corals and algae (see recent review and references therein (Lozano et

51 al., 2020)). Thus, the toxicity of BP3 combined with the possibility of

52 bioaccumulation indicates that BP3 might pose an ecological risk (Díaz-Cruz et al., 53 2019).

55 Wastewater treatment plants (WWTPs) are a major source of BP3 to the

56 environment, in addition to recreational water activities and industrial wastewater

57 discharges (Mao et al., 2018). Indeed, BP3 has been found in influents and effluents

58 of WWTPs (Ramos et al., 2016; Mao et al., 2018) in relatively high concentrations.

59 Often, the concentrations of BP3 are lower in the effluents of WWTPs than the

60 influents. This difference can be attributed to sorption to activated sludge and/or

61 biodegradation.

62

63 Biodegradation of BP3 has been shown to occur in different systems. Liu and

64 collegues observed degradation of BP3 in activated sludge microcosms (Liu et al.,

65 2012) and in microcosms using aquifer materials as an innoculum (Liu et al., 2013).

66 The data from this latter study was used as input in a model to better understand

67 the fate of UV filters, including BP3, in aquifers (Rodríguez-Escales and Sanchez-Vila,

68 2020). Among others, this model took into account sorption processses, both to

69 sediments and biomass, but also assumed that the UV-filters were degraded in a co- 
70 metabolic manner with the oxidation of sediment organic matter as the main

71 process.

72

73 The microorganisms responsible for the degradation in the studies described above

74 were not identified (Liu et al., 2012; Liu et al., 2013). So far the only bacterial strain

75 shown to be capable of BP3 degradation is Methyliphilus sp. strain FP-6, which

76 degraded BP3 co-metabolically when grown with several other carbon substrates

77 (Jin et al., 2019). The white root fungus Trametes versicolor can also degrade BP3

78 (Badia-Fabregat et al., 2012; Gago-Ferrero et al., 2012) but it is not known if this

79 degradation was a co-metabolic process since dried and sterilized sludge was used

80 as solid support in these experiments.

81

82 The objective of our study was to investigate the potential degradation of BP3 in

83 microcosms with WWTP sludge, to determine whether the BP3 degradation is

84 indeed co-metabolic and whether any bacterial species exist that can completely

85 mineralize BP3.

86

87

88 2. Materials and methods.

89

$90 \quad 2.1$ Chemicals

91 The UV filters used for biodegradation studies, 2-hydroxy-4-methoxybenzophenone

92 (BP3) and methylene bis-benzotriazolyl tetramethylbutylphenol (MBBT) were 
93 purchased from Sigma-Aldrich (Lyon, France), while 2-ethylhexyl salicylate (ES),

94 homosalate (HS), butyl methoxydibenzoylmethane (BM), octocrylene (OC),

95 diethylamino hydroxybenzoyl hexyl benzoate (DHHB), diethylhexyl butamido

96 triazone (DBT), and ethylhexyl triazone (ET) were kindly provided to us by Pierre

97 Fabre Pharmaceuticals. Analytical standards for the above-mentioned UV filters

98 were purchased from Sigma-Aldrich (Saint-Quentin-Fallavier, France). Analytical-

99 grade dichloromethane (DCM), 1-methyl-2-pyrrolidinone (NMP), methanol, formic

100 acid (98\%) and molecular grade formaldehyde were obtained from Sigma-Aldrich.

101 Pure water was obtained from an Elga Purelab Flex System (Veolia LabWater STI,

102 Antony, France). Glassware was cleaned with DCM and calcinated at $450{ }^{\circ} \mathrm{C}$ for 2

103 hours to remove all traces of organic matter.

104

1052.2 Sampling of sludge, initial culture and enrichment culture setup

106 The sludge was sampled from the Argelès-sur-mer (France) wastewater treatment

107 plant (WWTP) on August 24th, 2018, from the bottom of a clarifying tank. The

108 sludge was collected in glass mason jars and stored at $4{ }^{\circ} \mathrm{C}$ until utilized for

109 degradation experiments. The sludge contained $2765(+/-310) \mathrm{mg} / \mathrm{L}$ total

110 suspended solids (TSS) and the initial BP3 concentration was below the detection

111 limit for our analysis ( $4.6 \mathrm{ng} / \mathrm{g}$, see Fagervold et al. (2019)). For the initial

112 degradation experiments, $100 \mathrm{~mL}$ sludge was mixed with $500 \mathrm{~mL}$ freshwater

113 mineral media (OECD301) in a 1-L glass bottle (live). BP3 was added in methanol (2

$114 \mathrm{mg} / \mathrm{mL}$ ) to a final concentration of $10 \mu \mathrm{g} / \mathrm{ml}$. A sterile control (SC) was prepared by

115 autoclaving twice (48 hours apart) a 1-L bottle containing sludge and media at 120 
$116{ }^{\circ} \mathrm{C}$ for 20 minutes, followed by the addition of sodium azide $(1 \%)$ and then BP3. The

117 two bottles (one live and one SC) were incubated at $25^{\circ} \mathrm{C}$ in the dark and were

118 systematically shaken and opened inside a fume hood twice per week to allow

119 aeration.

120

121 An enrichment culture was initiated with inoculum from the initial flask that

122 showed degradation. The final theoretical BP3 concentration was about $10 \mu \mathrm{g} / \mathrm{mL}$

123 for Enrichment 1 (the first transfer), but this concentration was increased to a

124 theoretical concentration of $100 \mu \mathrm{g} / \mathrm{mL}$ for Enrichment 2 and subsequent

125 enrichments. To obtain a concentration of $100 \mu \mathrm{g} / \mathrm{mL}, 2 \mathrm{~mL}$ of a solution of BP3 in

126 acetone (2.5 mg/mL) was added to $100-\mathrm{mL}$ Erlenmeyer flasks containing $2 \mathrm{~g}$ of inert

127 sand. The acetone was left to evaporate overnight. Mineral media ( $50 \mathrm{~mL}$, as above)

128 was added and the flasks were autoclaved. Each month, the cultures were

129 transferred (1\% vol/vol) into new flasks with sand and BP3 (see Figure 1 for

130 diagram of the experimental setup). The cultures were incubated at $25^{\circ} \mathrm{C}$ in the

131 dark on a platform shaker at $100 \mathrm{rpm}$.

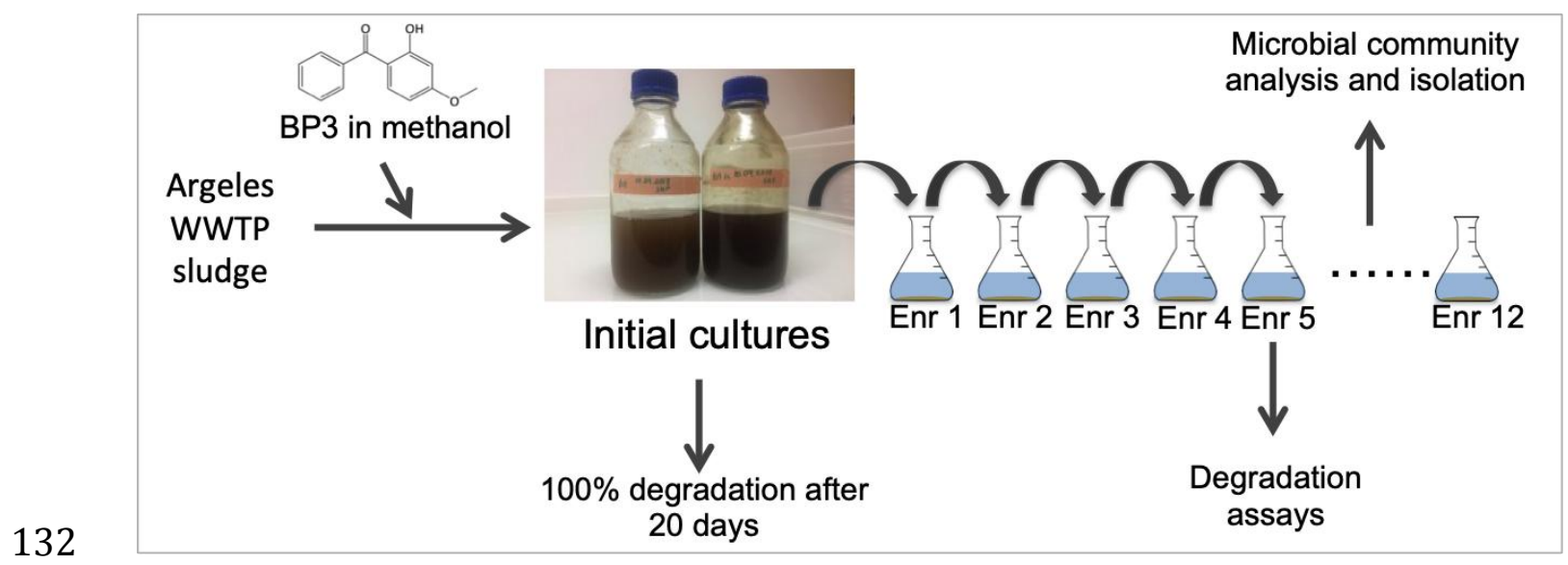

133 Fig. 1. Schematic of the experimental design. 


\section{Table 1}

135 Selected chemical properties and structure of the UV filters used in this study 136 (ordered by increasing molecular weight). Note the abbreviations that are used throughout.

138

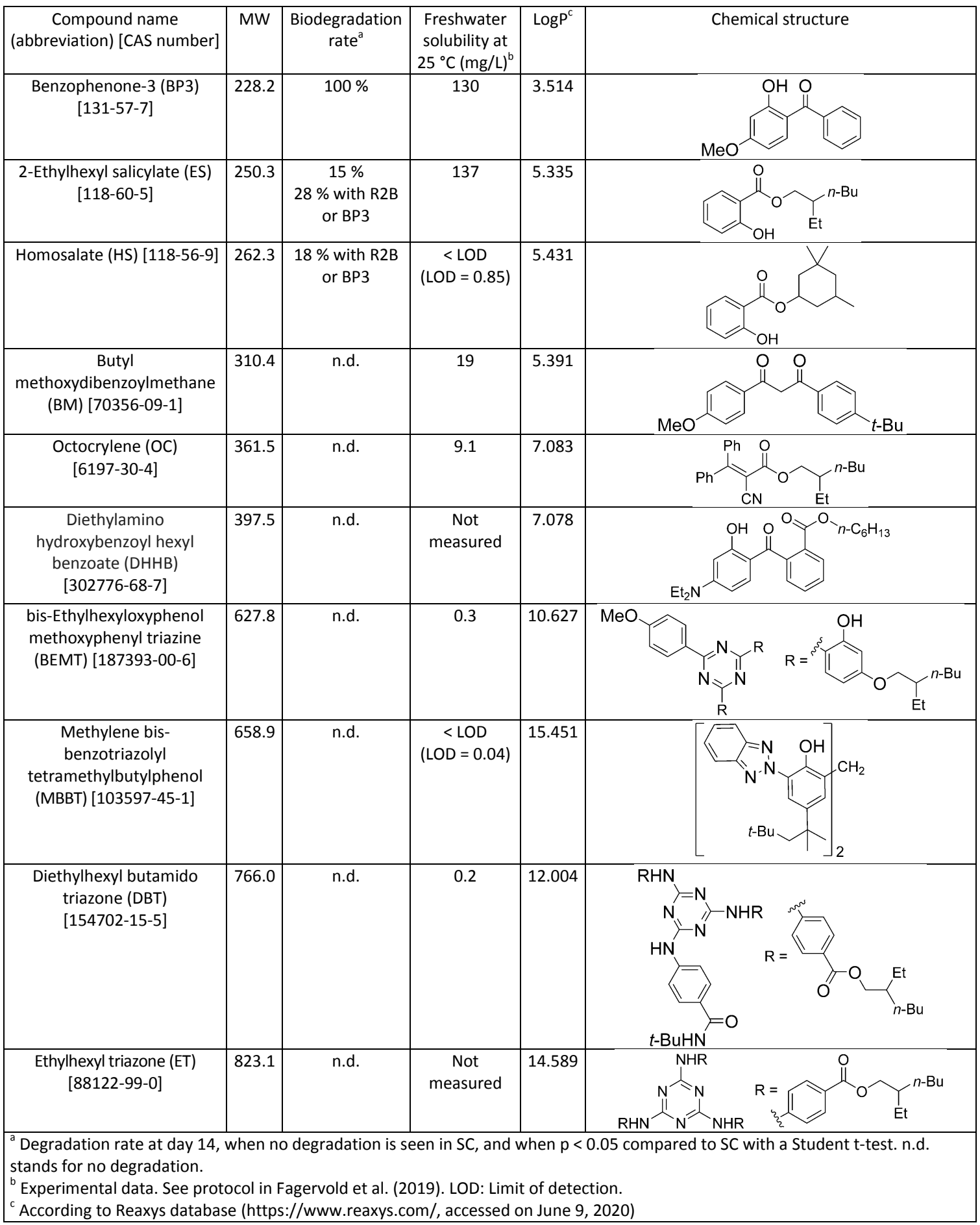

139 


\subsection{Biodegradation assays}

142 Biodegradation assays were conducted using 15-mL glass tubes with Teflon lined

143 caps (Pyrex, Analytic lab, France). The tubes were set up as for the enrichment

144 cultures, but with $0.2 \mathrm{~g}$ sand, $3 \mathrm{~mL}$ media, and care was taken so that for each batch

145 of degradation assays, the exact same amount of BP3 (around $100 \mu \mathrm{g} / \mathrm{mL}$ ) was

146 added to the tubes. Three tubes were sacrificed for each time-point. The tubes were

147 incubated at $25{ }^{\circ} \mathrm{C}$ after inoculation. For the enrichment cultures, the inoculum for

148 the assay was $150 \mu \mathrm{L}$ of supernatant after rigorous mixing of the enrichment

149 culture. Inoculum preparation for the biodegradation assay of strain BP14P was

150 done as follows: The strain was grown in $100 \%$ R2B broth (Thermo Fisher

151 Scientific, Illkirch-Graffenstaden, France) for about $40 \mathrm{~h}$ until the culture had

152 reached an optical density at $600 \mathrm{~nm}$ of approximately 1.0 . The cell suspension was

153 centrifuged at $4200 \mathrm{~g}$ for $10 \mathrm{~min}$ and subsequently washed 2 times with minimal

154 media before a final resuspension in minimal media $(4 \% \mathrm{v} / \mathrm{v})$. The cultures were

155 incubated at $25^{\circ} \mathrm{C}$ in the dark on a rotary shaker at $100 \mathrm{rpm}$.

156

1572.4 BP3 extraction

158 Two different protocols were used for the extraction of BP3, one for the initial

159 biodegradation experiments and another for the biodegradation assays for

160 enrichment cultures and isolated strains.

161

162 For the initial cultures containing WWTP sludge, $5 \mathrm{~mL}$ slurry was taken in duplicate

163 from each flask for each timepoint, both live and SC. The slurry was centrifuged (950 
$164 \mathrm{x} \mathrm{g}$ for $20 \mathrm{~min}$ ) to separate the aqueous and solid phases. The aqueous and solid

165 phases were then extracted and analyzed separately. The supernatant (aqueous

166 phase) was transferred to a new tube and subjected to liquid/liquid extraction with

167 acidified ( $0.1 \%$ formic acid) DCM. This was achieved by adding $5 \mathrm{~mL}$ acidified DCM

168 to the aqueous sample, mixing by vortexing and shaking overnight at $25^{\circ} \mathrm{C}$ in the

169 dark. The DCM fraction was decanted off and dehydrated with $\mathrm{Na}_{2} \mathrm{SO}_{4}$. The DCM was

170 then evaporated using the HT-4X system (Genevac, Biopharma Technologies,

171 Diemoz, France) and the residue was dissolved in $1 \mathrm{~mL}$ of NMP/water (8:2, v/v)

172 before analysis.

173

174 The solid phase was extracted as described by Fagervold and coworkers (Fagervold

175 et al., 2019) with modifications. Briefly, the pellet was frozen at $-80^{\circ} \mathrm{C}$, lyophilized

176 and extracted twice with $2 \mathrm{ml}$ acidified ( $0.1 \%$ formic acid) DCM $/$ methanol mix (1:1,

$177 \mathrm{vol} / \mathrm{vol}$ ) and sonicated for $10 \mathrm{~min}$. The supernatants were combined, evaporated

178 and re-dissolved in NMP/water (8:2, v/v) before HPLC analysis.

179

180 For the biodegradation assays, the whole tube containing sand and liquid media was

181 sacrificed for extraction at each timepoint. DCM (3 mL) containing an exact known

182 amount of MBBT (internal standard) was added to each tube. The tubes were mixed

183 by vortexing twice for 10 seconds, $1 \mathrm{~h}$ apart and shaken overnight at $100 \mathrm{rpm}$ at 25

$184{ }^{\circ} \mathrm{C}$ in the dark. After a brief sonication, $1 \mathrm{~mL}$ of the DCM phase was transferred to a

185 HPLC vial and diluted 20X in DCM before HPLC analysis. 
188 The UV filters were analyzed using an Ultimate $3000^{\mathrm{TM}}$ HPLC system, equipped with

189 a DAD detector (Thermo Fisher Scientific) and a Phenomenex Kinetex Biphenyl 2.6

$190 \mu \mathrm{m}, 150 \times 4.6 \mathrm{~mm}$ column as previously described (Fagervold et al., 2019) with

191 some minor modifications. The injection volume was $5 \mu \mathrm{l}$ and the samples were

192 diluted in 100\% DCM. We expanded the analysis described in Fagervold et al.

193 (2019) to include all targeted UV-filters. The calibration curves and retention times

194 of all the different UV filters (Table 1) were determined as described by Fagervold

195 and coworkers (Fagervold et al., 2019). The recovery rate was above $85 \%$ for the

196 extraction of BP3 in the initial sludge microcosms. The recovery rate for the

197 degradation assays were variable for the different UV filters, ranging from $63 \%$ for

198 ES to $93 \%$ for OC. However, the extraction efficiency was repeatable for each UV

199 filter over time, which is the most important factor for the detection of degradation 200 activity.

202 For determination of possible BP3 degradation products, we also performed a 203 UHPLC-MS/MS analyses as described by Stien and coworkers (Stien et al., 2019).

204 The data were acquired using the Trace Finder ${ }^{\mathrm{TM}} 3.1$ software and were processed 205 with FreeStyle ${ }^{\mathrm{TM}}$ and Compound Discoverer ${ }^{\mathrm{TM}}$ (all from Thermo Fisher Scientific).

207 2.6 Microbial community analysis of enrichment cultures

208 DNA was extracted using a Maxwell@ 16 LEV Blood DNA Kit (Promega,

209 Charbonnières-les-Bains, France) with the Maxwell ${ }^{\circledR} 16$ MDx Instrument (AS3000; 
210 Promega) following the manufacturer's instructions and with an initial lysing step.

211 Briefly, $2 \mathrm{~mL}$ of supernatant was transferred to a microcentrifuge tube and

212 centrifuged at $14500 \mathrm{xg}$ for 10 minutes. The pellet was resuspended in $300 \mu \mathrm{L}$

213 MilliQ water and $300 \mathrm{~mL}$ of the lysing buffer from the Maxwell ${ }^{\circledR} 16$ LEV Blood DNA

214 Kit was added to "lysing matrix B beads" (MP Biochemicals, Illkirch, France) and

215 homogenized for $20 \mathrm{~s}$ at $6 \mathrm{~m} / \mathrm{s}$ on a FastPrep-24 $4^{\mathrm{TM}} 5 \mathrm{G}$ Instrument (MP biochemicals).

216 After extraction, the DNA was stored at $-80^{\circ} \mathrm{C}$ until further analysis.

217 The composition and diversity of the bacterial communities in enrichment cultures

218 were determined by Automated Ribosomal Intergenic Spacer Analysis (ARISA) and

219 by Illumina sequencing (RTL genomics, Texas, USA). The ARISA was performed as

220 described by Fisher et al. (Fisher MM and Triplett EW, 1999) with minor

221 modifications. Briefly, for the PCR we utilized the intergenic spacer primers 1406F

222 and 23SRY (Fisher MM and Triplett EW, 1999) and the KAPA2G Fast HotStart

223 ReadyMix (Roche, Analytic Lab, St Mathieu de Treviers, France) with the following

224 PCR cycling parameters: $94^{\circ} \mathrm{C}$ for 3 minutes, 30 cycles of $94{ }^{\circ} \mathrm{C}$ for $15 \mathrm{~s}, 55^{\circ} \mathrm{C}$ for 15

$225 \mathrm{~s}$ and $72{ }^{\circ} \mathrm{C}$ for $30 \mathrm{~s}$, then a final elongation of $72{ }^{\circ} \mathrm{C}$ for $1 \mathrm{~min}$. The products were

226 purified, denatured and injected into a 16 capillary Applied Biosystems Sequencer

227 3130XL (Thermo Fisher Scientific) together with the internal standard

228 MapMarker® X-Rhodamine Labeled 50-1000 bp (Bioventures Inc., Tennessee, USA)

229 for the determination of peak lengths. For the analysis, individual fragment lengths

230 (within a $0.1 \mathrm{bp}$ "error range") were considered as separate Operational Taxonomic

231 Units (OTUs) and the relative abundance of each OTU was calculated by dividing the

232 area of the peak by the total area of the chromatogram after $200 \mathrm{bp}$. Furthermore, 
233 we only took into account peaks contributing to more than $1 \%$ of the relative peak

234 area. Concerning the Illumina sequencing analysis, the DNA was sent to RTL

235 genomics where paired end, $2 \times 300 \mathrm{bp}$ MiSeq Sequencing was performed using

236 standard conditions of the sequencing provider. We opted for dual indexing and

237 used the bacterial primers 341F (CCTACGGGNGGCWGCAG) and 806R

238 (GACTACHVGGGTATCTAATCC) (Herlemann et al., 2011). The sequences were

239 processed using Qiime2 (Bolyen et al., 2019). Briefly, the sequences were quality

240 filtered, stitched, denoised and clustered using dada2. Representative sequences

241 were classified using the Naive Bayes classifier and the Silva 132 database as a

242 reference. Our two samples (Enr 11 and Enr 12) yielded about 41000 and 47000

243 sequences, of which 39000 and 44000, respectively, belonged to a single OTU. There

244 were a total of 37 OTUs in the two samples, but most were present at very low

245 relative abundances.

246

$247 \quad 2.7$ Strain isolation and sequencing

248 The supernatant of an actively degrading enrichment culture transferred 7 times

249 (Enrichment 7, or Enr 7) was diluted 100 fold and spread on R2B agar and

250 incubated for 3 days at $25^{\circ} \mathrm{C}$ in the dark. Several colony morphologies were

251 observed and each morphotype was re-streaked on R2B agar to ensure purity.

252 These strains were tested for BP3 degradation activity and one positive strain,

253 BP14P, was further characterized. DNA was extracted as described above and

254 sequenced on the same sequencer used for ARISA. Here, we used universal bacterial

255 primers $27 \mathrm{~F}$ and $1492 \mathrm{R}$ in the first PCR and then the internal primers $907 \mathrm{R}, 804 \mathrm{~F}$ 
256 and S8 for the sequencing reactions realized by the dideoxy reaction Sanger

257 sequencing using the BigDye ${ }^{\mathrm{TM}}$ Terminator v3.1 Cycle Sequencing Kit (Thermo

258 Fischer) and the manufacturer's protocol.

2602.8 Flow Cytometry

261 Strain BP14P cells were counted throughout the degradation assay. The glass tubes

262 were vortexed and $1 \mathrm{~mL}$ of cell suspension was transferred to a microcentrifuge

263 tube before adding glutaraldehyde (1\% v/v final concentration). The tubes were

264 incubated at $4{ }^{\circ} \mathrm{C}$ in the dark for 15 minutes before flash freezing with liquid $\mathrm{N}_{2}$. The

265 samples were kept at $-80{ }^{\circ} \mathrm{C}$ until analysis. Samples were defrosted at room

266 temperature and incubated with the nucleic acid stain SYBRGreen I (Molecular

267 Probes) for $15 \mathrm{~min}$ at room temperature in the dark before enumeration (Marie et

268 al., 1997) using a FACSCanto flow cytometer (BD-Biosciences) equipped with optics

269 fiber emitted light (407, 488 and $633 \mathrm{~nm})$. Fluorescent $1.002 \mu \mathrm{m}$ beads

270 (Polysciences Inc., Europe) were added to each sample as an internal standard to

271 normalize cell properties and to compare cell populations. Accurate analyzed

272 volumes and subsequent estimations of cell concentrations were calculated using

273 Becton-Dickinson TrucountTM beads. Total bacterial cells (TBA) were enumerated

274 according to the variations of light scatter properties (relative cell size) and green

275 fluorescence related to nucleic acid content.

278 3. Results and discussion 
2803.1 Degradation of BP3 in initial sludge microcosms and enrichment cultures

281 To detect BP3 degradation, the concentration of BP3 in the amended flask

282 containing active sludge was compared with the amended flask containing sterilized

283 sludge. The theoretical added total BP3 concentration was $10 \mu \mathrm{g} / \mathrm{mL}$ slurry and the

284 slurry contained approximately $2 \mathrm{mg} / \mathrm{mL}$ dry matter. We analyzed the aqueous and

285 the solid phase separately and it was clear that some BP3 partitioned onto the solid

286 phase in the slurry (Figure 2). This fraction was bioavailable since we could not

287 detect any BP3 in either the solid or the aqueous phase after 20 days of incubation.

288 The concentration in the SC remained approximately the same after 20 days,

289 showing that this is not an artifact due to abiotic sorption processes. Thus, we

290 observed a complete degradation of BP3 in live cultures compared to the SC after 20

291 days.

292

293

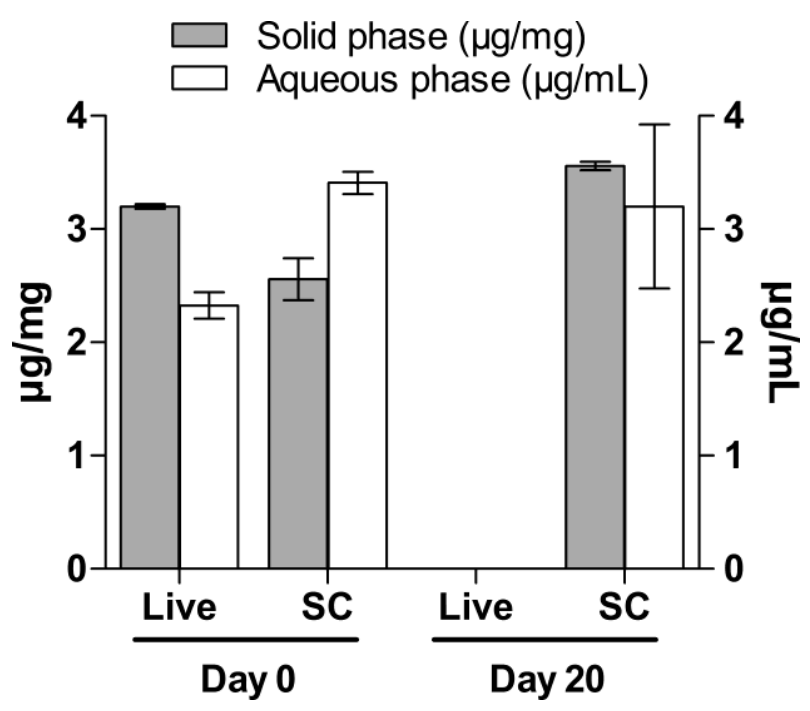

294 Fig. 2. BP3 concentrations in initial microcosms with WWTP sludge. BP3

295 concentrations in the aqueous phase $(\mu \mathrm{g} / \mathrm{mL}$, white bars $)$ and in the solid phase $(\mu$ 
$296 \mathrm{~g} / \mathrm{mg}$, grey bars) at day 0 and after 20 days of incubation. Live, active degrading

297 slurries and SC, sterile control.

299 The live culture actively degrading BP3 was transferred into an Erlenmeyer flask

300 containing $10 \mu \mathrm{g} / \mathrm{mL}$ BP3 (Enrichment 1, Enr 1). After 30 days, the Enr 1 culture

301 was transferred into a flask containing a higher BP3 concentration $(100 \mu \mathrm{g} / \mathrm{mL})$

302 (see figure 1), Enr 2. We added sand to the flasks with the hypothesis that it may

303 provide a solid support for the microorganisms. The cultures were transferred

304 every 30 days to further enrich BP3 degrading microorganisms. To maintain a

305 selective pressure on the microbial community, the only available carbon source for

306 the microorganisms was BP3. We could clearly see growth in the Erlenmeyer flask

307 based on the turbidity of the medium.

308

309 After 5 consecutive transfers, we verified the degradation activity of the Enr 5

310 enrichment culture by performing biodegradation assays in separate tubes. After 7

311 days of incubation, we could only detect trace amounts BP3 in the live

312 biodegradation assays, while the SC showed no decrease compared to day-0

313 samples. This was also observed in another biodegradation assay from Enr 9 (after

3149 transfers) after 5 days. Thus, it was clear that these enriched cultures degrade BP3

315 in a relatively fast manner.

316

3173.2 Microbial communities in enrichment cultures

318 


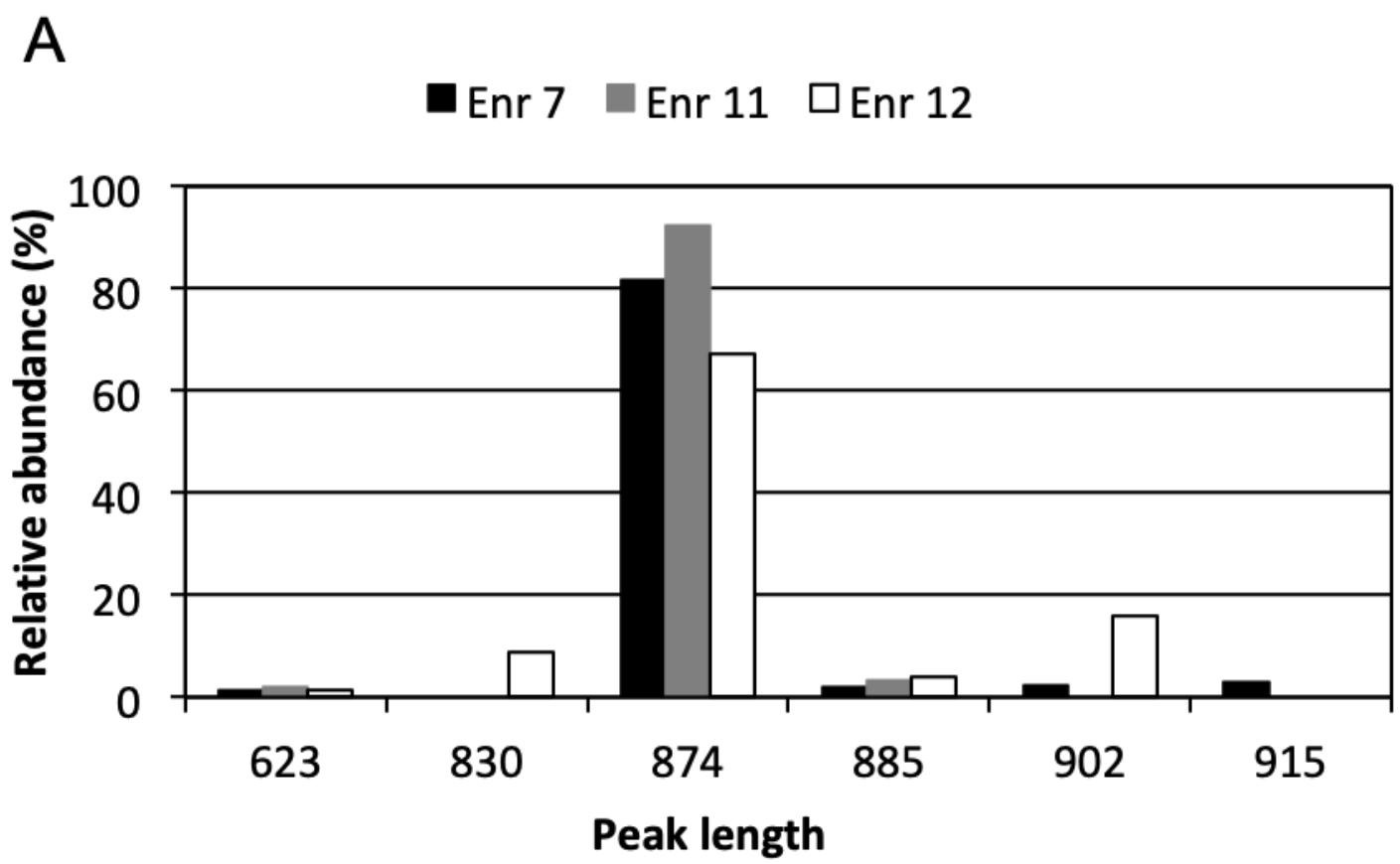

B

Enr $11 \square$ Enr 12

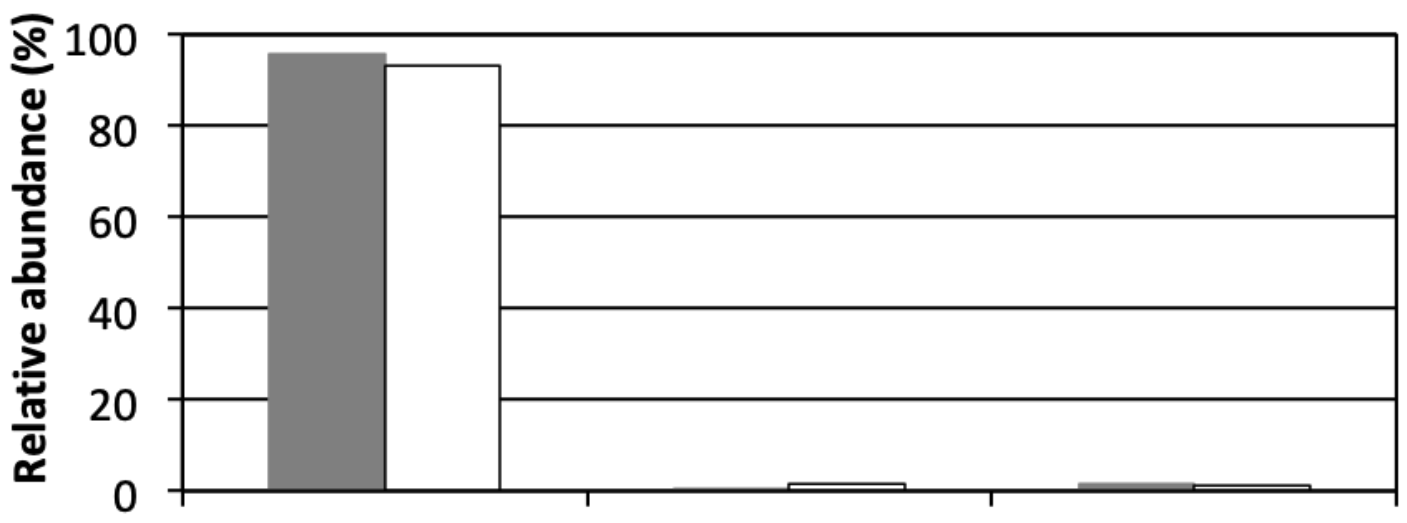

Sphingomonas Methylophilus sp. Achromobacter sp. wittichii sp.

OTUs

320 Fig. 3. Analysis of the microbial community diversity in BP3 degrading enrichment

321 cultures. (A) ARISA analysis of enrichment cultures "Enr 7" (black bars), "Enr 11"

322 (grey bars) and "Enr 12" (white bars) where each peak is one "OTU" and the relative

323 abundance is based upon area of each peak. (B) Relative abundance of different 
324 OTUs based upon Illumina sequencing in "Enr 11" (grey bars) and "Enr 12" (white 325 bars).

327 In order to estimate the diversity and stability of the enrichment cultures degrading 328 BP3, we performed ARISA of several enrichments and confirmed these results with 329 Illumina sequencing. We extracted DNA of cultures at day-4 after transfer and this

330 was done for different transfers (Enr 7,11 and 12). Briefly, ARISA is based upon the 331 concept that different bacteria have different sized intergenic spacers between the

332 16S rRNA gene and the 23S rRNA gene on their chromosome. An ARISA profile will 333 give an approximation of the microbial diversity of a sample, with one peak

334 representing one "OTU". From the ARISA we could see 5 different main peaks

335 (Figure 3A) and it was clear that the enrichment cultures were dominated by one

336 specific bacterium corresponding to a peak length of $874 \mathrm{bp}$. This was confirmed

337 with the results from the Illumina sequencing, where we detected only 3 major

338 OTUs, with a clear dominance of an OTU identified as Sphingomonas wittichii with a

339 relative abundance of about $95 \%$ in both Enr 11 and 12 (Figure 3B). We

340 hypothesized that this strain was responsible for the degradation of BP3 in these

341 enrichment cultures.

342

3433.3 Isolation and identification of the BP3 mineralizing strain BP14P

344 The most predominant strain in the enrichment cultures, BP14P, was isolated and

345 its degradation capability tested in minimal media (OECD301) and in minimal media 
346 amended with $10 \%$ R2B media. This was done to investigate whether strain BP14P

347 would degrade BP3 when other carbon sources were present.

348

349

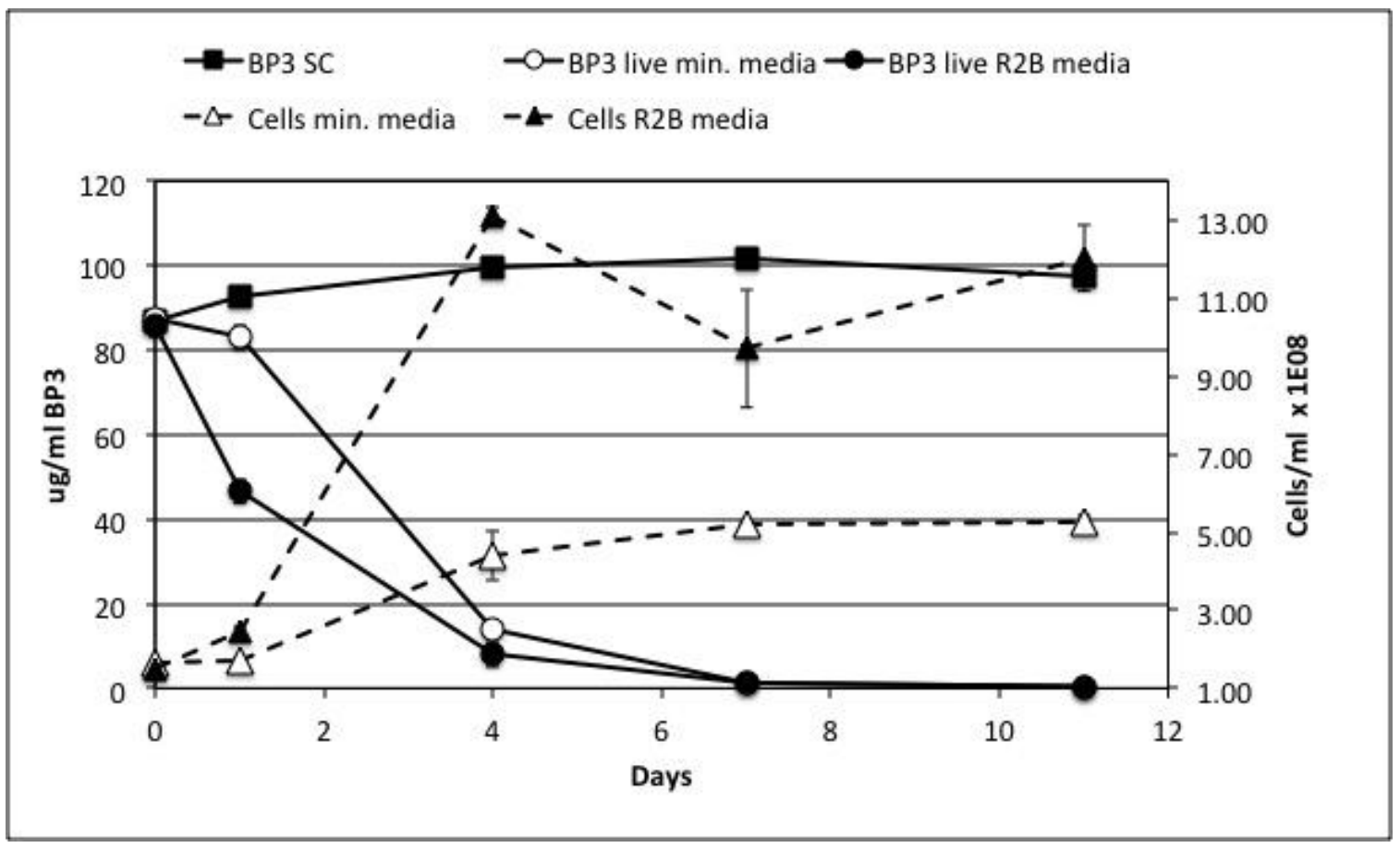

350

351 Fig. 4. Degradation of BP3 by Sphingomonas wittichiii sp. strain BP14P coupled to

352 growth. BP3 concentrations in sterile controls (black), BP3 concentrations in live

353 cultures with minimal media (open circles), BP3 concentrations in live cultures with

354 minimal media and $10 \%$ R2B media (black circles), cells per ml in cultures with

355 minimal media (open triangles) and cells per ml in cultures with minimal media and

356 10\% R2B media (black triangles).

357

358 
359 Strain BP14P degraded BP3 relatively fast as we could detect an almost 50\%

360 degradation after one day in cultures amended with R2B media, and 90\%

361 degradation after 4 days in both cultures with R2B but also in cultures with minimal

362 media (Figure 4). This degradation was clearly linked to growth since the

363 concentration of cells increased with time in cultures where the only carbon source

364 was BP3. We hypothesize that this strain completely mineralized BP3 and used BP3

365 as both carbon and energy source. To the best of our knowledge, this is the first

366 report showing a growth dependent degradation of BP3 in a pure strain.

368 A BLAST comparison of the 16S rRNA gene sequence of strain BP14P (1150 bp)

369 showed that it was $100 \%$ identical to Sphingomonas wittichii DC-6, isolated from

370 activated sludge (KC410868) and only one base pair different (1149/1150) to the

371 widely studied strain $S$. wittichii RW1 (NR_074268.1). DC-6 can mineralize the

372 herbicides alachlor, acetochlor, and butachlor (Chen et al., 2013) through $N$ -

373 dealkylation activity by a Rieske non-heme iron oxygenase system (Chen et al.,

374 2014). S. wittichii RW1 was first isolated from an urban river sample (Wittich et al.,

375 1992) and is able to degrade a plethora of aromatic compounds, like chlorinated

376 dibenzo-p-dioxins (DDs) and dibenzofurans (DFs) and to grow on DD and DF as sole

377 carbon and energy sources (Wittich et al., 1992). The first step in the degradation of

378 DD and DF is carried out by a dioxygenase and interestingly many of the genes

379 responsible for degradation of aromatic compounds are present on megaplasmids in 380 both strains Sphingomonas wittichii RW1 and DC-6 (Armengaud et al., 1998; Cheng 
381 et al., 2019; Miller et al., 2010). Indeed, this feature seems to be common in

382 Sphingomonas that degrade xenobiotics (Basta et al., 2004).

383

3843.4 Putative degradation pathway of BP3

385 During the HPLC-UV analysis, we could clearly detect an UV absorbing peak at an

386 earlier retention time than BP3 in some samples. To identify this peak and other

387 putative degradation products or intermediates, we analyzed several samples using

388 LC-MS/MS and molecular networks (MN) constructed by means of the Global

389 Natural Products Social Molecular Networking (GNPS) platform (Wang et al., 2016)

390 (https://gnps.ucsd.edu/). GNPS is a MS/MS data community sharing and curation

391 platform. Its MN tool organizes all MS/MS spectra recorded in complex mixtures of

392 compounds by families of analogous compounds, each grouped in one MN. This

393 enables the user to highlight possible degradation products in samples without any

394 presupposition of the chemical structure. In the present MN analysis, the number of

395 similar fragments was set to 2 , and the minimum cosine for linking two parent ions

396 was set to 0.7 . With these parameters, only one compound clustered with BP3, with

397 a parent mass at $m / z 215.070\left([\mathrm{M}+\mathrm{H}]^{+}\right)$. This compound was identified as BP1, a

398 BP3 demethylation product (Figure 5). BP1 was detected in high concentrations in

399 day 1 samples of the degradation assay with S. wittichii BP14P when R2B was

400 added. At this timepoint, BP3 was already about 50\% degraded. This peak was

401 detected only at trace levels in the following timepoints, meaning that BP1 was

402 rapidly degraded. This initial demethylation reaction has been previously reported

403 to be a probable degradation step in activated sludge microcosms (Liu et al., 2012) 
404 and as one probable pathway for BP3 degradation by Methylophilus sp. strain FP-6

405 (Jin et al., 2019).

406 


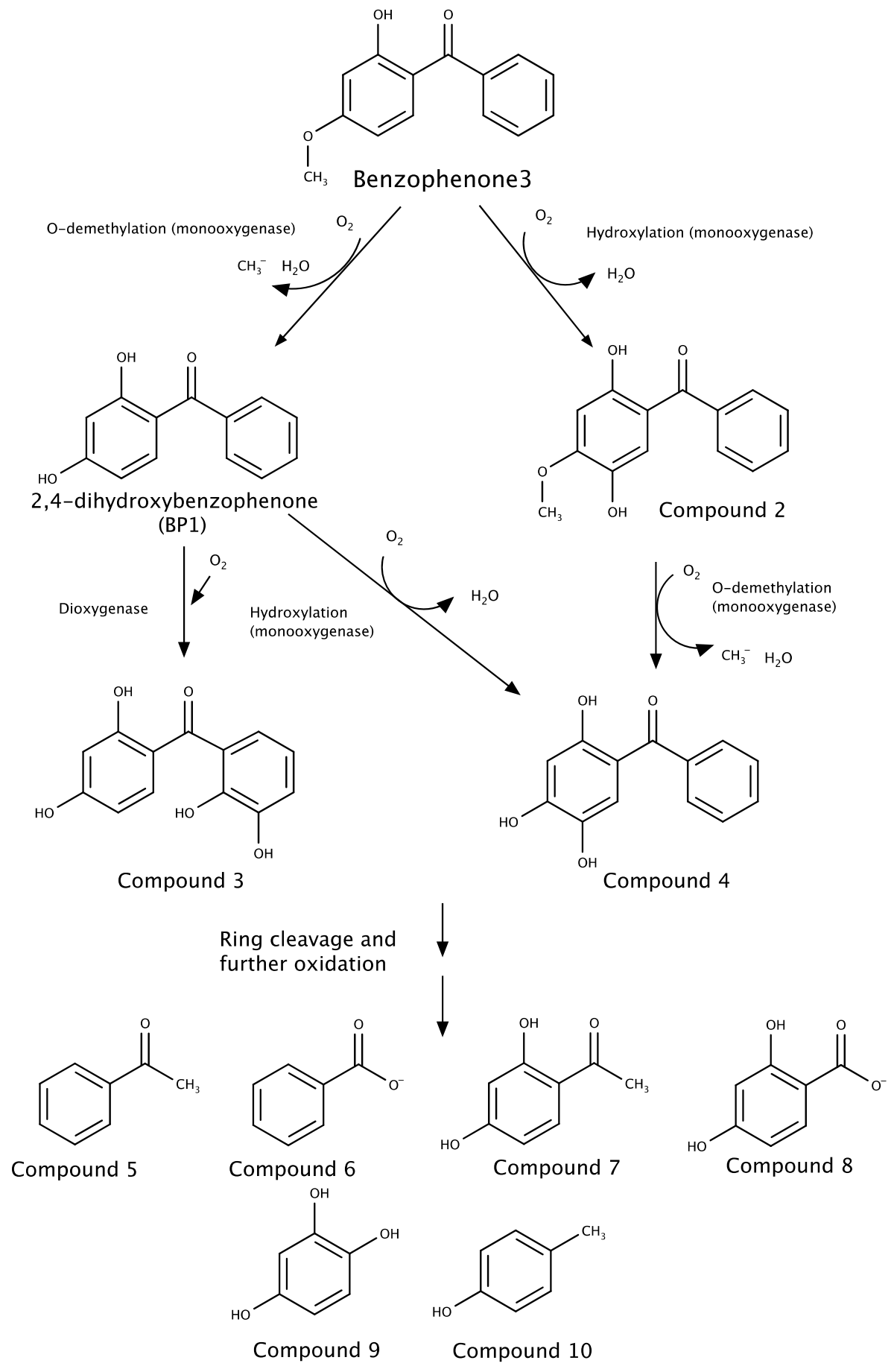

408 Fig. 5. Putative degradation pathway of BP3. 
410 We investigated other possible degradation pathways by submitting the BP3

411 structure to an online pathway prediction tool (Gao et al., 2010) and then searching

412 for particular exact masses of the predicted products $\left(\mathrm{m} / \mathrm{z}\right.$ of corresponding $[\mathrm{M}+\mathrm{H}]^{+}$

413 ions) in all the LC-MS profiles of our samples. Based upon the prediction, another

414 possible first step is a hydroxylation of the benzene ring (Compound 2 in Figure 5).

415 An ion corresponding to this compound was detected in some of our samples, as

416 was compound 4 . However, we did not detect compound $\mathbf{3}$ in any of our samples.

417 Based upon these results we hypothesize that the main degradation pathway

418 involves an initial demethylation of BP3 to BP1, followed by a hydroxylation to give

419 4. However, an initial hydroxylation of BP3 yielding compound 2 and a following

420 demethylation to result in compound 4 might be a minor pathway.

422 Jin and colleagues identified other compounds in Methylophilus sp. strain FP-6

423 cultures degrading BP3 (Jin et al., 2019). The presence of these compounds, not

424 depicted in Figure 5, suggested a degradation pathway involving hydroxylation of

425 BP3 and ring cleavage, but no demethylation. We did not find any evidence for this

426 pathway in S. wittichii BP14P. This might be due to the different nature (co-

427 metabolism versus growth linked) of the degradation process of the two different

428 strains in question.

429

430 Compounds 5-9 are examples of possible products after cleavage based upon the

431 prediction system. However, these low molecular weight compounds could not be

432 detected by our LC system that analyzed molecules between $133 \mathrm{Da}$ and $2000 \mathrm{Da}$. 
433 Compound 10 was detected by Liu et al. (2012), but was not predicted by the 434 prediction tool.

4363.5 UV filter degradation capabilities of strain BP14P are limited

437 We tested the capability of S. wittichii BP14P to degrade other UV filters, listed in 438 Table 1. Indeed, Miller et al. (2010) suggest that one of the reasons why S. wittichii

439 RW1 is so successful at degrading substrates with low water solubility might be

440 because of the abundance of TonB-dependent receptors, which can act as

441 transporters of aromatic compounds. Further, because the expression of some 442 dioxygenases (like dioxygenases dxnA1A2) have shown to be substrate dependent

443 (Armengaud et al., 1998), we also added BP3 to parallel assays to investigate

444 whether the putative expression of genes involved in degradation of BP3 can

445 stimulate the degradation of other aromatic compounds. Accordingly, we tested the

446 UV filters listed in Table 1 alone in biodegradation assays, as well as with extra

447 carbon (10\% R2B) and with BP3.

449 We incubated S. wittichii sp. BP14P with the 9 different UV filters for 14 days. BP3

450 was over $95 \%$ degraded in all the assays where it was added. However, we detected 451 very little degradation of the other UV filters (Table 1). The only other UV filter that 452 was partially degraded with no other carbon sources present was ES (15\% after 14 453 days). S. wittichii BP14P degraded ES slightly more when BP3 and other carbon 454 sources were present, namely $28 \%$ after 14 days. Finally, HS was $18 \%$ degraded 455 after 14 days when BP3 and other carbon sources were present. 
457 To summarize, S. wittichii BP14P did not degrade other UV filters to a great extent.

458 This specificity could be due to limited bioavailability of the other UV filters, a

459 limitation of putative transporters, or potentially, a limitation in the genes involved

460 in degradation.

461

$462 \quad 3.6$ What drives the specificity of BP3 degradation by strain BP14P?

463 Other researchers have observed that BP3 can be biodegraded. Liu et al. (2012)

464 found that BP3 was completely degraded after 42 days of incubation in both aerobic

465 and anaerobic microcosms also using inoculum from a WWTP. This suggests that

466 several groups of bacteria could be possible degraders, but this was not investigated

467 by Liu and collegues. Methylophilus sp. strain FP-6 was shown to co-metabolically

468 degrade BP3, degrading $15 \%$ of BP3 after 8 days when no other carbon source was

469 provided but degrading BP3 to a higher extent when other carbon sources were

470 present (Jin et al., 2019). Based on the data provided, we believe that Methylophilus

471 sp. strain FP-6 degraded BP3 co-metabolically. Strikingly, strain BP14P was very

472 specifically enriched in the cultures through many transfers, suggesting there were

473 no other bacteria present in the sludge that could degrade BP3 in a growth

474 dependent manner or in an equally efficient manner as strain BP14P.

475

476 Even though the $16 \mathrm{~S}$ rRNA gene of strain BP14P was $99.99 \%$ and $100 \%$ identical to

477 S. wittichii RW1 and DC-6, respectively, the functional similarity between these

478 strains remains to be investigated through a more polyphasic approach, including 
479 genome sequencing. Interestingly, $S$. wittichii RW1 has a very specific dioxygenase 480 activity that enables it to degrade DD and DF (Armengaud et al., 1998) and thus we

481 hypothesize that $S$. wittichii BP14P degrades BP3 through the activity of at least one 482 specific mono- or dioxygenase responsible for the initial demethylation (see figure

483 4) or another limiting step in the degradation pathway. We base this hypothesis on

484 the fact that the mono- or dioxygenase activity needed for BP3 degradation did not

485 seem to be widely distributed as no other bacteria were enriched in these cultures.

486 However, whether it uses a homologue of the $S$. wittichii RW1 enzyme, remains to be 487 investigated.

489 S. wittichii strains seem to be especially suited to degrade xenobiotics. For example

490 S. wittichii RW1 has extreme redundancy in its use of aromatic compound

491 metabolism (Coronado et al., 2012). This group of microorganisms generally

492 contains megaplasmids containing degradation genes and horizontal gene transfer

493 seems to be very common. Importantly, it is well known that $S$. wittichii RW1 can

494 survive and retain its degradation capability in soil when amended for

495 bioremediation purposes (Megharaj et al., 1997). All this makes it particularly

496 fascinating to enlarge the degradation repertoire of this group to include UV filters 497 and BP3.

499 4. Conclusions and perspectives

500 The extensive use of BP3 has resulted in ubiquitous BP3 contamination in various 501 environments, including in WWTPs and in many aquatic ecosystems (Fagervold et 
502 al, 2019). For a complete environmental risk assessment of BP3, it is important to

503 understand its fate and all the processes the molecule is subjected to. Degradation,

504 though either co-metabolism or mineralization is an important factor in this

505 assessment. We show here that BP3 can be completely degraded in a few days in

506 WWTPs by S. wittichii BP14P. Since BP3 can be utilized by a bacterium as an energy

507 source it then ensues that BP3 has the potential to be degraded in other

508 environmental compartments than WWTP sludge. As a consequence, the long-term

509 accumulation of BP3 in the environment could be less likely than previously

510 assumed. However, once released into marine ecosystems, it is as yet unknown

511 whether BP3 can be degraded. This question should be the subject of future studies,

512 as well as performing similar degradation testing on other sunscreen UV filters, with

513 a priority on the most toxic UV filters including octinoxate, octocrylene and

514 homosalate

515

516 Acknowledgements:

517 We would like to thank Cécile Villette for performing the sequencing of strain BP14P

518 and Maeva Duboeuf for help with chemical extractions. This work was carried out in

519 conjunction with the European Marine Biological Resource Centre (EMBRC-ERIC-

520 Banyuls-sur-Mer Oceanographic Observatory, OOB). We are grateful to the

521 BIO2MAR platform for providing access to instrumentation and especially to Nyree

522 West for technical help concerning the ARISA procedure and for reading through the

523 manuscript. We would like to thank Christophe Salmeron of the BioPIC Imaging and

524 Cytometry platform (OOB) for performing the flow cytometry and the technical 
525 support of EMBRC-France, whose French state funds are managed by the ANR

526 within the Investments of the Future program under reference ANR-10-INBS-02. We

527 would also like to thank the local council (Communauté de Communes Albères-Côte

528 Vermeille-Illibéris) who provided access to the WWTP site for sampling. This work

529 was financially supported by the Pierre Fabre Dermo-Cosmetic Laboratories in

530 France.

531

\section{Figure captions}

533 Figure 1. Schematic of the experimental design.

534

535 Figure 2. BP3 concentrations in initial microcosms with WWTP sludge. BP3

536 concentrations in the aqueous phase $(\mu \mathrm{g} / \mathrm{mL}$, white bars $)$ and in the solid phase $(\mu$

$537 \mathrm{~g} / \mathrm{mg}$, grey bars) at day 0 and after 20 days of incubation. Live, active degrading

538 slurries and SC, sterile control.

539

540 Figure 3. Analysis of the microbial community diversity in BP3 degrading

541 enrichment cultures. (A) ARISA analysis of enrichment cultures Enr 7 (black bars),

542 Enr 11 (grey bars) and Enr 12 (white bars) where each peak is one OTU and the

543 relative abundance is based upon area of each peak. (B) Relative abundance of

544 different OTUs based upon Illumina sequencing in Enr 11 (grey bars) and Enr 12

545 (white bars).

546 
547 Figure 4. Degradation of BP3 by Sphingomonas wittichiii sp. strain BP14P (left axis)

548 and growth followed by flow cytometry (right axis). BP3 concentrations in sterile

549 controls (SC, black square), BP3 concentrations in live cultures with minimal media

550 (open circles), BP3 concentrations in live cultures with minimal media

551 supplemented with $10 \%$ R2B media (black circles), cell concentrations of cultures

552 with minimal media (open triangles) or minimal media supplemented with $10 \%$

553 R2B media (black triangles).

554

555

556 Figure 5. Putative degradation pathway of BP3. Hypothesized degradation pathway

557 of BP3 based upon the online prediction tool "EAWAG-BBD Pathway Prediction

558 System"(http://eawag-bbd.ethz.ch/predict/)

559

560

561

562

563

564 References:

565 Armengaud, J., Happe, B., Timmis, K.N., 1998. Genetic analysis of dioxin dioxygenase

566 of Sphingomonas sp. Strain RW1: catabolic genes dispersed on the genome. J.

$567 \quad$ Bacteriol. 180, 3954-3966.

568 Badia-Fabregat, M., Rodríguez-Rodríguez, C.E., Gago-Ferrero, P., Olivares, A., Piña, B.,

569 Díaz-Cruz, M.S., Vicent, T., Barceló, D., Caminal, G., 2012. Degradation of UV 
filters in sewage sludge and 4-MBC in liquid medium by the ligninolytic fungus Trametes versicolor. J. Environ. Manage. 104, 114-120. https://doi.org/10.1016/j.jenvman.2012.03.039

573 Barr, L., Alamer, M., Darbre, P.D., 2018. Measurement of concentrations of four

Basta, T., Keck, A., Klein, J., Stolz, A., 2004. Detection and Characterization of chemical ultraviolet filters in human breast tissue at serial locations across the breast. J. Appl. Toxicol. JAT 38, 1112-1120. Conjugative Degradative Plasmids in Xenobiotic-Degrading Sphingomonas Strains. J. Bacteriol. 186, 3862. https://doi.org/10.1128/JB.186.12.3862Alexander, H., Alm, E.J., Arumugam, M., Asnicar, F., Bai, Y., Bisanz, J.E., Bittinger, K., Brejnrod, A., Brislawn, C.J., Brown, C.T., Callahan, B.J., CaraballoRodríguez, A.M., Chase, J., Cope, E.K., Da Silva, R., Diener, C., Dorrestein, P.C., Douglas, G.M., Durall, D.M., Duvallet, C., Edwardson, C.F., Ernst, M., Estaki, M., Fouquier, J., Gauglitz, J.M., Gibbons, S.M., Gibson, D.L., Gonzalez, A., Gorlick, K., Guo, J., Hillmann, B., Holmes, S., Holste, H., Huttenhower, C., Huttley, G.A., Janssen, S., Jarmusch, A.K., Jiang, L., Kaehler, B.D., Kang, K.B., Keefe, C.R., Keim, P., Kelley, S.T., Knights, D., Koester, I., Kosciolek, T., Kreps, J., Langille, M.G.I., Lee, J., Ley, R., Liu, Y.-X., Loftfield, E., Lozupone, C., Maher, M., Marotz, C., Martin, B.D., McDonald, D., McIver, L.J., Melnik, A.V., Metcalf, J.L., Morgan, S.C., Morton, J.T., Naimey, A.T., Navas-Molina, J.A., Nothias, L.F., Orchanian, S.B., 
Pearson, T., Peoples, S.L., Petras, D., Preuss, M.L., Pruesse, E., Rasmussen, L.B., Rivers, A., Robeson, M.S., Rosenthal, P., Segata, N., Shaffer, M., Shiffer, A., Trinh, P., Tripathi, A., Turnbaugh, P.J., Ul-Hasan, S., van der Hooft, J.J.J., Vargas, F., Vázquez-Baeza, Y., Vogtmann, E., von Hippel, M., Walters, W., Wan, Y., Wang, M., Warren, J., Weber, K.C., Williamson, C.H.D., Willis, A.D., Xu, Z.Z., Zaneveld, J.R., Zhang, Y., Zhu, Q., Knight, R., Caporaso, J.G., 2019. Reproducible, interactive, scalable and extensible microbiome data science using QIIME 2. Nat. Biotechnol. 37, 852-857. https://doi.org/10.1038/s41587-019-0209-9

Chen, Q., Wang, C.-H., Deng, S.-K., Wu, Y.-D., Li, Y., Yao, L., Jiang, J.-D., Yan, X., He, J., Li, 605 606

607 Chen, Q., Yao, L., Wang, C., Deng, S., Chu, C., He, J., 2013. Isolation and 608 609 610 characterization of acetochlor-degrading strain Sphingomonas sp. DC-6 and

611 Cheng, M., Yan, X., He, J., Qiu, J., Chen, Q., 2019. Comparative genome analysis reveals 612 the evolution of chloroacetanilide herbicide mineralization in Sphingomonas 613 wittichii DC-6. Arch. Microbiol. 201, 907-918. https://doi.org/10.1007/s00203-019-01660-w 
615 Coronado, E., Roggo, C., Johnson, D., van der Meer, J.R., 2012. Genome-Wide Analysis

616 of Salicylate and Dibenzofuran Metabolism in Sphingomonas Wittichii RW1.

617 Front. Microbiol. 3, 300. https://doi.org/10.3389/fmicb.2012.00300

618 Díaz-Cruz, M.S., Molins-Delgado, D., Serra-Roig, M.P., Kalogianni, E., Skoulikidis,

619 N.Th., Barceló, D., 2019. Personal care products reconnaissance in EVROTAS

620 river (Greece): Water-sediment partition and bioaccumulation in fish. Sci.

621 Total Environ. 651, 3079-3089.

622 https://doi.org/10.1016/j.scitotenv.2018.10.008

623 Fagervold, S.K., Rodrigues, A.S., Rohée, C., Roe, R., Bourrain, M., Stien, D., Lebaron, P., 624 2019. Occurrence and Environmental Distribution of 5 UV Filters During the 625 Summer Season in Different Water Bodies. Water. Air. Soil Pollut. 230, 172.

626 https://doi.org/10.1007/s11270-019-4217-7

627 Fisher, M.M., Triplett, E.W., 1999. Automated approach for ribosomal intergenic 628 spacer analysis of microbial diversity and its application to freshwater 629 bacterial communities. Appl Env. Microbiol 65, 4630-4636.

630 Gago-Ferrero, P., Badia-Fabregat, M., Olivares, A., Piña, B., Blánquez, P., Vicent, T.,

631 Caminal, G., Díaz-Cruz, M.S., Barceló, D., 2012. Evaluation of fungal- and

632 photo-degradation as potential treatments for the removal of sunscreens BP3

633 and BP1. Sci. Total Environ. 427-428, 355-363.

634 https://doi.org/10.1016/j.scitotenv.2012.03.089

635 Gao, J., Ellis, L.B., Wackett, L.P., 2010. The University of Minnesota

636 Biocatalysis/Biodegradation Database: improving public access. Nucleic

$637 \quad$ Acids Res 38, D488. 
638 Herlemann, D.P., Labrenz, M., Jürgens, K., Bertilsson, S., Waniek, J.J., Andersson, A.F., 639 2011. Transitions in bacterial communities along the $2000 \mathrm{~km}$ salinity 640 gradient of the Baltic Sea. ISME J. 5, 1571-1579.

641 https://doi.org/10.1038/ismej.2011.41

642 Jin, C., Geng, Z., Pang, X., Zhang, Y., Wang, G., Ji, J., Li, X., Guan, C., 2019. Isolation and 643 characterization of a novel benzophenone-3-degrading bacterium Methylophilus sp. strain FP-6. Ecotoxicol. Environ. Saf. 186, 109780.

645 https://doi.org/10.1016/j.ecoenv.2019.109780

646 Liu, Y.-S., Ying, G.-G., Shareef, A., Kookana, R.S., 2013. Degradation of Six Selected 647 Ultraviolet Filters in Aquifer Materials Under Various Redox Conditions. 648 Groundw. Monit. Remediat. 33, 79-88. https://doi.org/10.1111/gwmr.12027

650 Liu, Y.-S., Ying, G.-G., Shareef, A., Kookana, R.S., 2012. Biodegradation of the 651 ultraviolet filter benzophenone-3 under different redox conditions. Environ. 652 Toxicol. Chem. 31, 289-295. https://doi.org/10.1002/etc.749

653 Lozano C., Givens J., Stien D., Matallana-Surget S., Lebaron P., 2020. Bioaccumulation 654 and Toxicological Effects of UV-Filters on Marine Species, in: The Handbook 655 of Environmental Chemistry. Springer, Berlin, Heidelberg, pp. 1-46.

656 Mao, F., He, Y., Gin, K., 2018. Occurrence and fate of benzophenone-type UV filters in 657 aquatic environments: A review. Environ. Sci. Water Res. Technol. 5. $658 \quad$ https://doi.org/10.1039/C8EW00539G 
659 Marie, D., Partensky, F., Jacquet, S., Vaulot, D., 1997. Enumeration and Cell Cycle 660 Analysis of Natural Populations of Marine Picoplankton by Flow Cytometry 661 Using the Nucleic Acid Stain SYBR Green I. Appl. Environ. Microbiol. 63, 186. 662 Megharaj, M., Wittich, R.-M., Blasco, R., Pieper, D.H., Timmis, K.N., 1997. Superior 663 survival and degradation of dibenzo-p-dioxin and dibenzofuran in soil by 664 soil-adapted Sphingomonas sp. strain RW1. Appl. Microbiol. Biotechnol. 48, 665 109-114. https://doi.org/10.1007/s002530051024

666 Miller, T.R., Delcher, A.L., Salzberg, S.L., Saunders, E., Detter, J.C., Halden, R.U., 2010.

667 Genome sequence of the dioxin-mineralizing bacterium Sphingomonas 668 wittichii RW1. J. Bacteriol. 192, 6101-6102.

669 https://doi.org/10.1128/JB.01030-10

670 Molins-Delgado, D., Máñez, M., Andreu, A., Hiraldo, F., Eljarrat, E., Barceló, D., Díaz671 Cruz, M.S., 2017. A Potential New Threat to Wild Life: Presence of UV Filters 672 in Bird Eggs from a Preserved Area. Environ. Sci. Technol. 51, 10983-10990. 673 https://doi.org/10.1021/acs.est.7b03300

674 Ramos, S., Homem, V., Alves, A., Santos, L., 2016. A review of organic UV-filters in 675 wastewater treatment plants. Environ. Int. 86, 24-44.

676 https://doi.org/10.1016/j.envint.2015.10.004

677 Rodríguez-Escales, P., Sanchez-Vila, X., 2020. Modeling the fate of UV filters in 678 subsurface: Co-metabolic degradation and the role of biomass in sorption $679 \quad$ processes. Water Res. 168, 115192.

680 https://doi.org/10.1016/j.watres.2019.115192 
681 Stien, D., Clergeaud, F., Rodrigues, A.M.S., Lebaron, K., Pillot, R., Romans, P., 682 Fagervold, S., Lebaron, P., 2019. Metabolomics Reveal That Octocrylene Accumulates in Pocillopora damicornis Tissues as Fatty Acid Conjugates and Triggers Coral Cell Mitochondrial Dysfunction. Anal. Chem. 91, 990-995.

Suh, S., Pham, C., Smith, J., Mesinkovska, N.A., 2020. The banned sunscreen ingredients and their impact on human health: a systematic review. Int. J.

Wang, M., Carver, J.J., Phelan, V.V., Sanchez, L.M., Garg, N., Peng, Y., Nguyen, D.D., Dermatol. https://doi.org/10.1111/ijd.14824 Watrous, J., Kapono, C.A., Luzzatto-Knaan, T., Porto, C., Bouslimani, A., Melnik, A.V., Meehan, M.J., Liu, W.-T., Crüsemann, M., Boudreau, P.D., Esquenazi, E., Sandoval-Calderón, M., Kersten, R.D., Pace, L.A., Quinn, R.A., Duncan, K.R., Hsu, C.-C., Floros, D.J., Gavilan, R.G., Kleigrewe, K., Northen, T., Dutton, R.J., Parrot, D., Carlson, E.E., Aigle, B., Michelsen, C.F., Jelsbak, L., Sohlenkamp, C., Pevzner, P., Edlund, A., McLean, J., Piel, J., Murphy, B.T., Gerwick, L., Liaw, C.C., Yang, Y.-L., Humpf, H.-U., Maansson, M., Keyzers, R.A., Sims, A.C., Johnson, A.R., Sidebottom, A.M., Sedio, B.E., Klitgaard, A., Larson, C.B., Boya P, C.A., Torres-Mendoza, D., Gonzalez, D.J., Silva, D.B., Marques, L.M., Demarque, D.P., Pociute, E., O'Neill, E.C., Briand, E., Helfrich, E.J.N., Granatosky, E.A., Glukhov, E., Ryffel, F., Houson, H., Mohimani, H., Kharbush, J.J., Zeng, Y., Vorholt, J.A., Kurita, K.L., Charusanti, P., McPhail, K.L., Nielsen, K.F., Vuong, L., Elfeki, M., Traxler, M.F., Engene, N., Koyama, N., Vining, O.B., Baric, R., Silva, R.R., Mascuch, S.J., Tomasi, S., Jenkins, S., Macherla, V., Hoffman, T., Agarwal, V., 
Williams, P.G., Dai, J., Neupane, R., Gurr, J., Rodríguez, A.M.C., Lamsa, A., Zhang, C., Dorrestein, K., Duggan, B.M., Almaliti, J., Allard, P.-M., Phapale, P., Nothias, L.-F., Alexandrov, T., Litaudon, M., Wolfender, J.-L., Kyle, J.E., Metz, T.O., Peryea, T., Nguyen, D.-T., VanLeer, D., Shinn, P., Jadhav, A., Müller, R., Waters, K.M., Shi, W., Liu, X., Zhang, L., Knight, R., Jensen, P.R., Palsson, B.Ø., Pogliano, K., Linington, R.G., Gutiérrez, M., Lopes, N.P., Gerwick, W.H., Moore, B.S., Dorrestein, P.C., Bandeira, N., 2016. Sharing and community curation of mass spectrometry data with Global Natural Products Social Molecular Networking. Nat. Biotechnol. 34, 828-837. https://doi.org/10.1038/nbt.3597

714 Wittich, R.M., Wilkes, H., Sinnwell, V., Francke, W., Fortnagel, P., 1992. Metabolism of 715 dibenzo-p-dioxin by Sphingomonas sp. strain RW1. Appl. Environ. Microbiol.

716 $58,1005$.

717

718

719 